\section{$\underset{\substack{\text { hommes } \\ \text { \& migrations }}}{ }$}

\section{Hommes \& migrations}

Revue française de référence sur les dynamiques

migratoires

$1313 \mid 2016$

1983 , le tournant médiatique

\title{
Arezki Métref, La Traversée du somnambule. Chroniques du mentir-vrai
}

Préface de Boualem Sansal, Alger, éd. Koukou, 2015, 196 p.

\section{Mustapha Harzoune}

\section{(2) OpenEdition}

\section{Journals}

Édition électronique

URL : http://journals.openedition.org/hommesmigrations/3606

DOI : $10.4000 /$ hommesmigrations.3606

ISSN : 2262-3353

Éditeur

Musée national de l'histoire de l'immigration

Édition imprimée

Date de publication : 1 janvier 2016

Pagination : 170-171

ISBN : 978-2-919040-34-6

ISSN : 1142-852X

Référence électronique

Mustapha Harzoune, "Arezki Métref, La Traversée du somnambule. Chroniques du mentir-vrai », Hommes \& migrations [En ligne], 1313 | 2016, mis en ligne le 17 juin 2016, consulté le 24 septembre 2020. URL : http://journals.openedition.org/hommesmigrations/3606 ; DOI : https://doi.org/10.4000/ hommesmigrations.3606 
y a matière ì un document multimé dia. Mais, par trop impatient, Hassan Ben Alohamed se concentre-sur l'écri ture Variant les formes narratives, sans pathos excessif ni firoritures de style, it retrace l'évolution de son enquête jusqu'à... son éprouvante rencontre avectemeurtrier

Au delà du témoignage introspectifet deson intime conviction selon laquelle les tirs ont été délibérés et que justice
A'a pas été rendue, l'auteur nous invite ainsi à une réflexion rare sur les limites de l'entre soi, bousculant des mémoires lacunaires voire défaillantes, ycompris dans les milieux " militants" " eoncernés, mais it nous invite aussi à reconsidérer l'importance des dyna miques intra familiales dans la consti tutionet la préservation de la mémoire eollective.

Aogniss H. Abdallah

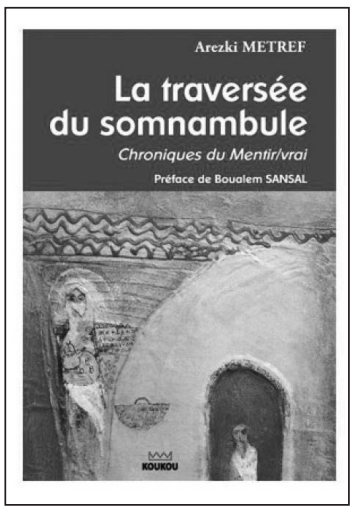

Arezki Métref

La Traversée

du somnambule.

Chroniques

du mentir-vrai

Préface de Boualem

Sansal, Alger,

Koukou, 2015, 196 p.

Journaliste, Arezki Métref appartient à cette génération qui a baigné dans les heures encore ensoleillées de la dictature algérienne, distribuée en courant alternatif, tantôt incongru, tantôt ennuyeux ou monstrueux. Avec d'autres, en l'occurrence avec Tahar Djaout et Abdelkrim Djaad, il participa, au tournant de la décennie 1990, à l'émergence d'" une société civile moderne ", comme l'écrit le préfacier, ici à la création d'une presse en rupture du nom de l'hebdo créé en janvier 1993 - avec le journalisme de papa. Djaout assassiné, Métref part en France. Reste cette "société civile " et les mots de
Sansal, vite oubliés ici : "Qu'aurait-elle fait si la grande Europe et la puissante Amérique avaient choisi de l'aider, elle, plutôt que le pouvoir militaire et les islamistes? Mais voilà, grandeur et puissance n'empêchent pas la myopie."

Métref est aussi un écrivain, adepte de la nouvelle, du roman, de la poésie ou de l'écriture théâtrale. Ce recueil illustre à merveille combien notre homme est d'abord un littéraire. Le titre déjà. Ces chroniques données au Soir d'Algérie se nomment les «Chroniques du mentir-vrai ", ce qui conduit d'entrée à Aragon. Quoi de mieux que les entrailles de la fiction, où mijotent indistincts vérités et mensonges, pour traduire la complexité d'une époque ou les subtilités d'une âme, rendre visible l'invisible, audible l'indicible, déposer ses tripes sur la table et faire entendre le bruit et la fureur du monde. S'il fallait s'en convaincre, l'élogieuse préface du grand Sansal finirait d'aiguiser la curiosité des moins pressés. Oui, la langue de Métref est superbe : légère, vive, 
ramassée, élancée et dans le même temps suggestive, irradiante, grâce à l'originalité des formules, poétiques et journalistiques.

Ces chroniques, rédigées à la première personne, mêlent les souvenirs des reportages à Berlin-Est, La Havane ou Varsovie; les rencontres, illustres, avec Derrida - "la décontraction du zazou algérois "-, Naguib Mahfouz, Jules Roy et "l'ambiguïté matricielle de la colonisation ", Nicolas Guillén ou encore André Chouraqui. II y ajoute ses goûts pour l'indispensable Albert Cossery, pour l'inspirateur, Kateb Yacine, pour Gabriel Garcia Marquez, Anna Seghers ou pour Kundera : à l'ombre de la dissidence percent les désillusions algériennes. Ici, la littérature préside même aux rencontres : Boris Vian avec une étudiante polonaise, Borges avec une hôtesse de l'air prénommée Tessa, fille d'Amar et de Germaine, dont il devient le "légataire d'une histoire désormais orpheline ». Fausse note avec Sandra : Mozart ouvre et ferme le bal.

Avec Kundera, il revisite la notion d'exil, privilégiant la figure de Calypso plutôt que celle de Pénélope, la part créatrice sur la nostalgie. D'exil il est bien sûr question ici. Une répétition avec le comédien Nafa Moualek et le metteur en scène Hama Méliani, ramène l'auteur à Rainer Maria Rilke et à quelques souvenirs de tribune avec Mohamed Dib. Le Soleil, boulevard de Ménilmontant à Paris, brille de l'éclat d'une jeune institution. Cette resucée des bistrots kabyles d'antan est devenu " moderne », "branchouille ». Le lieu évoque non seulement l'exil algérien mais aussi bien James Baldwin, Toni
Morrison ou Louise Michel, avant que, par on ne sait quelle pirouette, on se retrouve dans le Strasbourg des écrivains, ceux encore vivants mais menacés d'une fatwa (Salman Rushdie ou Taslima Nasreen), ceux dispensés de fatwa mais bien morts (Tahar Djaout ou Farag Fouda).

Du côté de l'Hay-les-Roses, on croise Assia Djebbar, dans la maison où elle vécut et qui fut un temps celle d'Elissa Rhaïs. Les brasseries parisiennes de l'exil algérien rappellent des pages de Klaus Mann. On y refait le monde. Il y a là le poète, intransigeant et tourmenté Ahmed Azegagh, l'écrivain Sadek Aïssat, le cinéaste Azzedine Meddour ou l'ami Nourredine Saadi. Ces cafés " où nous nous réunissions à plusieurs pour tenter de créer une association, pour partager la souffrance et mutualiser l'espoir ! "... Pour tromper l'illusion aussi : "Ce sentiment de solitude dans les métropoles occidentales dopées à la vitesse et à la performance, c'est la première chose que j'ai ressentie quand j'ai quitté ma tribu agitée pour me jeter dans la topographie de l'illusion."

"La topographie de l'illusion ", quelle formule!

Mustapha Harzoune 